\title{
Analysis of a low resistance concrete workability added with tire rubber fibers
}

\author{
Juan Rentería-Soto, Julio Roberto Betancourt-Chávez, Noel Silva-Barrón, Facundo \\ Cortés-Martínez
}

\begin{abstract}
The concrete is a mixture of cement, sand, gravel and water, it is classified into simple concrete and reinforced concrete. The workability, consistency and plasticity are fundamental aspects that a concrete mixture must have; the three main factors that are measured when make a mixture are: air content, slump and temperature. The reuse of tires helps to avoid the large accumulation of these and save oil for the manufacture of new. The use of modified concrete is not something new and many countries have been developing and applying it successfully in recent years. Most research focuses on measuring the mechanical properties of hardened concrete, leaving aside the properties of the fresh concrete. The objective of this research is to measure the incidence of the addition of rubber fibers from disused tires, with values of $10 \%$ and $15 \% .6$ parameters were measured to the fresh concrete, obtaining that few are not affected and some of them are modified in a positive way.
\end{abstract}

Index Terms - low resistance concrete, rubber fibers, disused tires, workability.

\section{INTRODUCTION}

\section{Concrete}

The concrete is a mixture of cement, fine aggregate, coarse aggregate and water [1]. It is classified into simple concrete and reinforced concrete. The concept of simple concrete is used when talking about a mixture conformed by Portland cement, coarse aggregates, fine aggregates and a moisturizer that produces the chemical reaction, without any extra reinforcement. Reinforced concrete is one that is used with some extra element to increase its properties or strength [2].

According to the Portland Cement Association [3], the workability, consistency and plasticity are fundamental aspects that a concrete mixture must have, being the workability the ease of placement, consolidation and finishing the fresh concrete, all this without its aggregates get segregate The three main factors that are measured when making a mixture are: air content, slump and temperature. [4] define the concrete slump as the greater or lesser difficulty of mixing, transporting, placing and compacting the concrete, explain

Juan Rentería Soto, Faculty of Engineering, Science and Architecture Juarez University of Durango State, (FICA-UJED). Gómez Palacio, Durango, México

Julio Roberto Betancourt Chávez, Faculty of Engineering, Science and Architecture Juarez University of Durango State, (FICA-UJED). Gómez Palacio, Durango, México

Noel Silva Barrón, student of Faculty of Engineering, Science and Architecture Juarez University of Durango State, (FICA-UJED). Gómez Palacio, Durango, México

Facundo Cortes Martínez, Faculty of Engineering, Science and Architecture Juarez University of Durango State, (FICA-UJED). Gómez Palacio, Durango, México that the property is directly affected by the cement paste and its water-cement ratio determined for each particular mixture. The concrete temperature is one of the most important factors that directly intervene in the quality, setting time and resistance of concrete [5].

\section{Tires}

Usually, the life of a tire is in proportion to the kilometers running, around 50,000 km [6]. The reuse of tires represents in addition to avoiding the large accumulation of these, saving oil for the manufacture of new, to manufacture one normal size car tire 32 liters of crude oil are needed, while for one recycled 11 liters are needed, in a truck tire (which is bigger) requires 100 liters and for one recycled 32 liters approximately, which constitutes a saving between $30 \%$ and $50 \%$ of material [7].

The use of modified concrete is not something new and many countries have been developing and applying it successfully in recent years [8]. The concrete presents a high compressive strength as the natural stones, but low resistance to traction around $10 \%$ of its resistance to compression [9]. In the research carried out on the addition of synthetic rubber to different cement-based mixtures for the manufacture of concrete and bricks, it has been found that, with the addition of rubber to mixtures, these tend to reduce their density, but in others of their properties they obtain good results being improved [10]. [11] made a mixture of Portland cement, which was added two more materials: crushed synthetic rubber and ash resulting from the burning of carbon, the test focused to obtain the flexure, compression and absorption characteristics of the concrete. [12] developed new concrete mixtures replacing the fine aggregate by three recycled materials: elastomers from tire treads, polypropylene and nylon fibers, found that concrete-rubber mixtures do not show segregation, but mixtures with nylon and polypropylene fibers do. [13] evaluated the effect of adding particles of tire waste on a cement paste. They determined that the flexural strength and modulus of elasticity increase with the addition of rubber particles in the cement pastes, indicating that the rubber-containing specimens show high hardness, but decrease the compressive strength. The geometry of the rubber particles that are added to the mixture is of the utmost importance as it directly influences the adherence they have with the cement paste, thereby also improving the tensile strength [14].

The majority of the investigations are directed to evaluate the mechanical properties of the hardened concrete added with rubber in different concentrations and as substitution of some of the base aggregates. The objective of this research is to 
measure the incidence of rubber fibers in the workability of low resistance concrete mixtures, adding $10 \%$ and $15 \%$ of the weight of the cement, the factors to be measured: temperature, density, slump, content of air, compactibility and workability.

\section{METHODOLOGY}

The materials were characterized according to the applicable Mexican standards (NMX) and the design of the concrete mixture was carried out for a compressive strength of $\mathrm{f}^{\prime} \mathrm{c}=150 \mathrm{~kg} / \mathrm{cm}^{2}$. The design slump was $150 \mathrm{~mm}$ with an approximation of $\pm 25 \mathrm{~mm}$. Maximum size of the aggregate $19 \mathrm{~mm}$, the design of the mixture was developed by the absolute volume method of the PCA [3].

Materials

- Portland Blended Cement (CPC 30 R)

- River sand

- Crushed limestone gravel

- Tire waste fibers (3-12 mm)

The designed mixture was taken and modified for the two addition percentages, leaving a mixture without aggregate (M1), a mixture with $10 \%$ (M2) and a mixture with 15\% (M3) Each mixture was elaborated and the parameters were measured.

\section{RESULTS}

The obtained results from the mixtures M1, M2 and M3 are shown in tables 1, 2 and 3 respectively, where it is observed that the temperature remains the same in the mixtures M1 and M3, the mixture M2 presenting a variation of only 1 degree Celsius. The density shows a decrease of mixtures 2 and 3 with respect to mixture 1 , being $0.86 \%$ and $1.87 \%$ respectively. The slump remains normal within the design parameters in mixtures 1 and 3, presented changes mixture 2 . The air content of the mixture 1 is $1 \%$, the mixtures 2 and 3 present a slight increase. The compactability shows no significant differences behaving similarly in the three mixtures. The workability presents considerable changes with respect to the mixture 1 since the mixture 2 decreases $22.23 \%$ while the mixture 3 increases its workability $5.93 \%$.

Table 1. Characteristics of the mixture without rubber.

\begin{tabular}{|c|c|}
\hline \multicolumn{2}{|c|}{ M1 } \\
\hline Temperature $\left({ }^{\circ} \mathbf{C}\right)$ & 28 \\
\hline Density $\left(\mathbf{k g} / \mathbf{m}^{3}\right)$ & 2232.21 \\
\hline Slump (mm) & 170 \\
\hline Air content & $1 \%$ \\
\hline Compactability & 0.99 \\
\hline Workability & $92.68 \%$ \\
\hline
\end{tabular}

Table 2. Characteristics of the mixture with $10 \%$ rubber addition.

\begin{tabular}{|c|c|}
\hline \multicolumn{2}{|c|}{ M2 } \\
\hline Temperature $\left({ }^{\circ} \mathbf{C}\right)$ & 29 \\
\hline Density $\left(\mathbf{k g} / \mathbf{m}^{\mathbf{3}}\right)$ & 2212.94 \\
\hline Slump $(\mathbf{m m})$ & 80 \\
\hline Air content & $2.10 \%$ \\
\hline Compactability & 0.96 \\
\hline Workability & $70.45 \%$ \\
\hline
\end{tabular}

Table 3. Characteristics of the mixture with $15 \%$ rubber addition.

\begin{tabular}{|c|c|}
\hline \multicolumn{2}{|c|}{ M3 } \\
\hline Temperature $\left({ }^{\circ} \mathbf{C}\right)$ & 28 \\
\hline Density $\left(\mathbf{k g} / \mathbf{m}^{3}\right)$ & 2190.46 \\
\hline Slump $(\mathbf{m m})$ & 150 \\
\hline Air content & $2.50 \%$ \\
\hline Compactability & 0.97 \\
\hline Workability & $98.61 \%$ \\
\hline
\end{tabular}

\section{CONCLUSION}

Of the six factors observed in the study, temperature and compatability are not affected by the addition of rubber fibers. The density decreases as a function of the percentage of rubber increase. The variation in the slump of the mixture 2 is attributed to lack of homogenization of the rubber, but not to the percentage of addition. It is concluded that the addition of rubber fibers improves the workability when the rubber is previously wetted, this because it provides water to the mixture, and decreases the density that could be a favorable point for some uses.

\section{ACKNOWLEDGMENT}

The authors would like to thank the Faculty of Engineering Sciences and Architecture of the Juárez University of the State of Durango for the support to the publication of this work.

\section{REFERENCES}

[1] [1] ACI Committee 318, 2014, "Building Code Requirements for Structural Concrete (ACI 318S-14) and Commentary (318RS-14)", American Concrete Institute, Farmington Hills, MI, 2014, 587 pp.

[2] IMCyC, 2008, "Determination of the compressive strength of concrete cylinders -Test method", The concrete in the work PROBLEMS, CAUSES AND SOLUTIONS, Mexican Institute of Cement and Concrete, pp 67-71, November 2008.

[3] PCA, 2004, "Design and Control of Concrete Mixtures", Portland Cement Association, Skokie, Illinois, EE.UU., 2004, 448 pp.

[4] Hernández, H., \& Sánchez, H. (2015). Mechanical behavior of a concrete mix using shredded tires as a replacement for $15 \%, 25 \%$ and $35 \%$ of the fine aggregate volume for a concrete for structural use (Bachelor thesis). Catholic University of Colombia, Bogotá, Colombia.

[5] IMCyC, 2007, "tests to fresh concrete, second of seven parts", The concrete in the work PROBLEMS, CAUSES AND SOLUTIONS, Mexican Institute of Cement and Concrete, pp 7-9, October 2007.

[6] Sánchez Juan, R. (2012). Second life of used tires. Chemistry alive, 11 (1), 24-39. 
[7] Flores, D. (2013). Design, manufacture and characterization of constructive applications of dry consistency concretes with additions of organic and inorganic materials of tires out of use (NFUs) (Phd thesis). University of Las Palmas de Gran Canaria, Las Palmas de Gran Canaria, Spain.

[8] Torres, H. (2014). Assessment of mechanical properties and durability of concrete added with rubber tires residues (Master's Thesis). Colombian School of Engineering Julio Garavito, Bogotá, Colombia.

[9] Gutiérrez de López, Libia (2003). Concrete and other materials for construction. National University of Colombia, Manizales, Colombia. ISBN 958-9322-82-4.

[10] Arroyave, G. J. P., Restrepo, S. M. V., \& Vásquez, D. H. G. (2017). Recycled rubber applications: A review of the literature. Neogranadine Science and Engineering, 27(2), 1.

[11] Yilmaz, A., \& Degirmenci, N. (2009). Possibility of using waste tire rubber and fly ash with Portland cement as construction materials. Waste Management, 29(5), 1541-1546.

[12] García, M. (2007). Feasibility of substitution of the fine aggregate of the concrete by fibers of thermoplastics and recycled elastomers (Master's Thesis). Simon Bolivar University, Caracas, Venezuela.

[13] Segre, N., \& Joekes, I. (2000). Use of tire rubber particles as addition to cement paste. Cement and concrete research, 30(9), 1421-1425.

[14] Alfonso, J., Badillo O. (2011). Evaluation of the energy dissipation capacity of concrete with metallic fibers and rubber waste tire (Bachelor thesis). Pontifical Javeriana University, Bogotá Colombia.

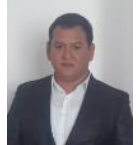

Rentería-Soto Juan, is a research professor at the Faculty of Engineering, Sciences and Architecture of the Juarez University of the State of Durango, completed his master's degree in civil engineering at the Autonomous University of Ciudad Juárez and is currently studying his doctorate at the Autonomous University of Chiapas It works on the characterization of mechanical properties of new materials and structural behavior.

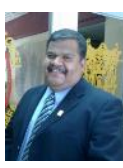

Betancourt-Chávez Julio Roberto, obtained the degree at the University of Sonora through the Doctorate in Civil Engineering CUMex in March 2015, was Head of Postgraduate in the Faculty of Engineering, Sciences and Architecture of the Juarez University of the State of Durango, during the period from February 2007 to September 2016.

The Research Group "Construction Technology" belongs. He is currently a professor-researcher at the same Faculty and works on projects for the development of new materials in construction using waste as additives or replacement of aggregates. He has participated in congresses at the National and International level and published research articles in indexed journals.personal profile which contains their education details, their publications, research work, membership, achievements, with photo that will be maximum 200-400 words.

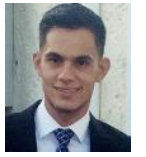

Silva-Barrón Noel, is a student of the career of civil engineering in the Faculty of Engineering Sciences and Architecture of the Juarez University of the State of Durango.

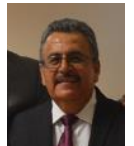

Cortés-Martínez Facundo, Doctor in Engineering, He is currently a professor-researcher at the Faculty of Engineering Sciences and Architecture of the Juarez University of the State of Durango, author of articles and books on sanitation, optimization and mathematical models 